\title{
Article \\ Socio-Economic Determinants for Biochar Deployment in the Southern Highlands of Tanzania
}

\author{
Peter Msumali Rogers ${ }^{1} * \mathbb{D}$, Mathias Fridahl ${ }^{2} \mathbb{D}$, Pius Yanda ${ }^{1}$, Anders Hansson ${ }^{2} \mathbb{D}$, Noah Pauline ${ }^{1}$ \\ and Simon Haikola ${ }^{3}$ D \\ 1 Institute of Resource Assessment, University of Dar es Salaam, Dar es Salaam P.O. Box 35091, Tanzania; \\ pyanda@gmail.com (P.Y.); pauline.noah@udsm.ac.tz (N.P.) \\ 2 Centre for Climate Science and Policy Research, Department of Thematic Studies, Environmental Change, \\ Linköping University, 58183 Linköping, Sweden; mathias.fridahl@liu.se (M.F.); \\ anders.n.hansson@liu.se (A.H.) \\ 3 Department of Thematic Studies-Technology and Social Change, Linköping University, \\ 58183 Linköping, Sweden; simon.haikola@liu.se \\ * Correspondence: rogerspeter120@gmail.com; Tel.: +255-714-968-295
}

check for updates

Citation: Rogers, P.M.; Fridahl, M.; Yanda, P.; Hansson, A.; Pauline, N.; Haikola, S. Socio-Economic Determinants for Biochar Deployment in the Southern Highlands of Tanzania. Energies 2022, 15, 144. https://doi.org/10.3390/ en15010144

Academic Editor: Daniel

W. McCollum

Received: 28 October 2021

Accepted: 22 December 2021

Published: 26 December 2021

Publisher's Note: MDPI stays neutral with regard to jurisdictional claims in published maps and institutional affiliations.

Copyright: (C) 2021 by the authors. Licensee MDPI, Basel, Switzerland. This article is an open access article distributed under the terms and conditions of the Creative Commons Attribution (CC BY) license (https:// creativecommons.org/licenses/by/ $4.0 /)$.

\begin{abstract}
Biochar may contribute to both agricultural productivity and atmospheric carbon dioxide removal. However, despite the many potential upsides of adding biochar to amend carbon-depleted soils in sub-Saharan Africa, deployment is largely lacking. This paper explores the socio-economic factors that can explain tendencies to avoid action. Based on a survey of 172 farming households, key informant interviews, and focus group discussions in the Mbeya and Songwe regions of Tanzania, which were targeted for a biochar aid program in 2014, several socio-economic drivers behind the continued use of biochar deployment were identified in this follow-up study. A key deployment driver was the increased crop yields, perceived to be the result of adding biochar to soils, increasing yields from 1 metric ton per hectare to 3 metric tons per hectare. Food security and family income were cited as the main reasons to engage in biochar production and use. Climate change mitigation and increased resilience were other key reasons that motivated adoption. In terms of socio-economic factors, farmers with low education and income, the majority being males aged 40-60 years, contributed to low adoption rates in the study area. Respondents often cited the alternative usage of biochar feedstocks, lack of government involvement or extension services, traditions, and farming customs as the main constraints limiting biochar deployment.
\end{abstract}

Keywords: biochar; socio-economic influence; food security; climate adaptation and mitigation

\section{Introduction}

Applying biochar to agricultural soils has been put forward as a potential remedy for carbon-depleted and acidic soils, and as a method to adapt agriculture to the increasingly harsh impacts of climate change [1]. Biochar is a form of charcoal produced by heating biomass under conditions of minimal oxygen using a pyrolysis process [2]. The pyrolysis process can be broadly classified as gasification at greater than $800{ }^{\circ} \mathrm{C}$, with fast pyrolysis from $800{ }^{\circ} \mathrm{C}$ to $500{ }^{\circ} \mathrm{C}$, and slow pyrolysis below $500{ }^{\circ} \mathrm{C}$. Slow pyrolysis is recommended for biochar production [3]. Due to its high aromaticity, the carbon in biochar is highly recalcitrant in soils because the carbonized product becomes resistant to decomposition [3]. When biochar is applied, the soil stores atmospheric carbon trapped in the char, and thus helps to mitigate climate change [4]. Depending on the properties of the biochar and the soil, the carbon storage can be stable for decades, or even centuries [5]. Biochar properties may also improve the soil's water-holding capacity, thus reducing erosion and nutrient leakage [6]. Biochar can balance soil $\mathrm{pH}$, especially in the kinds of acid soils that are abundant in Tanzania; therefore, it ameliorates the effects of bacterial communities, to the benefit of yields [7]. 
The literature on biochar is substantial, with a strong focus on process optimization and soil analysis [8]; however, little is known about the socio-economic drivers and barriers to biochar deployment $[9,10]$. This gap in the literature on biochar is also notable in the context of Tanzania. A recent mapping of Tanzanian biochar initiatives shows that, despite the prospects for biochar to improve yields and reduce vulnerability, the adoption of biochar systems remains limited. Many of the original initiatives have been terminated, not least because of a lack of sustained development aid or a viable business model. One example is notable: the biochar production and application initiative in the Southern Highlands of Tanzania [11]. Previous research has shown that biochar deployment in developing countries is influenced by socio-economic factors [12]. These factors include age, sex, education, income, occupation, beliefs, farm size, and the availability of feedstocks [13]. This article seeks to substantiate the claims and hypotheses presented in previous research through a systematized empirical approach. Based on a survey of 172 rural farming households, the article seeks to answer two research questions:

What factors explain farmers' decisions to use, or refrain from using, biochar? To what extent do age, sex, education, and income influence farmers' perceptions and their production and use of biochar?

This paper provides a unique empirical understanding of the socio-economic drivers and barriers to the use of biochar, and aspires to identify issues and problems to be followed up in forthcoming work. The lack of previous empirical research on the topic prevents the specification of hypotheses. The research questions have therefore deliberately been kept broad and explorative. The article begins by providing a background to Tanzanian biochar initiatives; then, Section 2 describes the methods of data collection and statistical analysis. Section 3 presents the results, and Section 4 draws upon previous literature to discuss plausible explanations for the detected response patterns. Finally, Section 5 concludes, offering several recommendations and areas for further studies in the field of socio-economic drivers and barriers to biochar deployment in Tanzanian agriculture.

Agriculture provides daily livelihoods for $80 \%$ of Tanzanians [14]. However, it is threatened by the impacts of climate change, which are spread unevenly across the country. The rainfall models project less predictability and more volatility in the intensity of rainfall [15]. This has already led to - and will likely continue to lead to-a decline in agricultural productivity that threatens food security [16]. In addition to regional differences, the impacts of climate change strike poor subsistence farmers disproportionately hard, because they are more vulnerable to change due to a low adaptive capacity [17]. Therefore, a technology that would increase crop production, reduce vulnerability to the impacts of climate change, and mitigate further climate change would seem perfectly suited to the needs of the time.

The use of biochar in Tanzania was originally promoted by the Black Earth Project, initiated in 2014 in the Southern Highlands in a partnership between Tembo Coffee Company, the Tanzanian NGO MIICO, and the U.S. NGO Radio Lifeline [18]. The initiative aimed to increase coffee yields through amending the soil with biochar to improve the soil structure and moisture content in the study area, which had been affected by an extended dry spell. The partnering organizations also sought to improve cost efficiency and decrease dependence on externally sourced agricultural inputs. Hence, the initiative used maize cobs as feedstock for local biochar production, thus also functioning as a waste-management project. Trials compared coffee plants grown in soil with biochar, with biochar combined with nitrogen, phosphorus, and potassium (NPK) fertilizers, and crops without biochar. The results indicated positive effects from the addition of biochar, with yield increases of approximately $30 \%$ in some of the trials [19]. In addition, the coffee produced from plants grown in biochar-enriched soils scored, on average, two points higher on the Specialty Coffee Association of America's quality cupping scale than those grown without biochar. The trials also indicated a 50\% cut in fertilizer input costs, and it was reported that about 7000 smallholder farmers had been trained to produce and apply biochar to soils in the Southern Highlands [20]. This achievement has created awareness and knowledge im- 
parted to smallholder farmers in the study area that helps to maintain the use and even spread of the technology.

However, the spread of biochar practices among smallholder farmers in Tanzania is limited and has progressed slowly. A few biochar initiatives were identified and described in [21]. For example, an initiative by Norges Vel produced 100 metric tonnes of rice-husk biochar, which enriched the soil in 10 demonstration plots and improved crop yields in Mbalali, Kilombero, and Idodi [22]. A second initiative was designed by Trans-SEC and executed in the Kilosa and Chamwino districts. This approach combined biochar from maize cobs and 25\% NPK fertilizers, which increased dry-matter harvest by $83 \%$ compared with the control plots. Smallholder farmers in this area considered biochar to be agricultural waste management because the area produces a large quantity of maize that results in large piles of unutilized cobs [23]. Thirdly, the New Forests Company (NFC) initiative in Kilolo, Iringa, uses eucalyptus waste from pole production to produce biochar. The initiatives aimed to manage waste, improve food security in villages around eucalyptus farms, and provide a new revenue stream for the company [24]. Additionally, the EnergySanitation-Agriculture Nexus initiative in Kagera introduced micro gasifier stoves to utilize agricultural wastes as feedstocks and sources of energy for cooking, while ensuring a supply of biochar for the farms. The project results show that biochar improved kitchen gardens and increased crop yields in Karagwe [25]. Nevertheless, the reasons for smallholder farmers to engage with and sustain biochar systems remain understudied, although some research is ongoing in sub-Saharan Africa. Further research on these issues may hold the key to designing successful biochar systems for the large numbers of smallholder farms that exist in developing countries.

Previous research has shown that biochar deployment in developing countries is influenced by age, sex, education, income, occupation, beliefs, farm size, and availability of feedstocks. For example, the author of [26] revealed that $20 \%$ of smallholder farmers in the Nkolbisson Forest in central Cameroon had only a few years of formal education. It was further reported that $55 \%$ of farmers agreed that the collection, storage, and transportation of feedstocks, as well as the pyrolysis itself, were expensive. Moreover, farmers aged over 40 years were more willing to apply biochar than younger ones, due to access to resources such as land, labor, and finance. Together, these factors led biochar investments to be perceived as uncertain by reducing application levels and expected benefits. After biochar training and the establishment of demonstration plots, smallholder farmers improved soil conditions and increased yields. Through 41 interviews with participants in nine biochar initiatives in Tanzania, complemented with seven field visits to production and application sites, this study shows that lack of education and financial means among farmers hindered the spread of the technology. For example, the biochar produced was left to be used as cooking fuel instead of a soil amendment [11]. The author of [27] revealed that men played a central role in deciding about biochar, i.e., building kilns, mobilizing feedstocks, operating pyrolysis, and applying biochar in farms in Haiti, Costa Rica, and India. The involvement of women was minimal, through the use of cookstoves and retort pyrolizers. Producing biochar while cooking would attract more women to engage in biochar production and application. Studies by $[28,29]$ reported that local beliefs and constructions can influence smallholder farmers' participation in biochar technology. It was found that farmers preferred to buy pre-packed biochar rather than make their own, because biochar making resembles charcoal production, which is an occupation of lowerclass people. Therefore, engaging in biochar production was understood to run the risk of reducing the farmers' social status.

The author of [30] reported that farmers with large farms are more likely to adopt biochar technologies than those with small farms. This is because they can afford to devote sections of their land to experiment with the innovation. However, applying biochar to small farms is easy, because little feedstock is needed. In addition, the application process takes less time compared with large farms. This is consistent with [31], who found that small farm size is conducive to input-intensive innovation, in comparison with large farms, 
which need more input that may not be available. This article, therefore, systematically maps views on biochar among smallholder farmers in the Southern Highlands of Tanzania, where such farmers have been introduced to small-scale biochar production for application on local farms.

\section{Materials and Methods}

In order to substantiate the relationships between socio-economic variables and biochar deployment indicated in previous research, this study returned to an area in the Southern Highlands of Tanzania in which farmers had previously been introduced to biochar through the Black Earth Project, initiated in 2014 [18]. The research was based on a structured questionnaire with a sample of respondents drawn from smallholder farmers in villages targeted by the Black Earth Project. The three villages are located in the districts Rungwe, Mbozi, and Mbeya Rural between latitudes $7^{\circ}$ and $9^{\circ}$ south of the equator, longitudes $32^{\circ}$ and $35^{\circ}$ east of Greenwich. The Black Earth Project was launched as a public-private "Coffee Partnership for Tanzania", managed by the German Investment Corporation, DEG. Under this scheme, the Tembo Coffee Company initiated a biochar sub-project in the Southern Highlands of Tanzania in collaboration with MIICO, an NGO that focuses on improving agricultural and marketing possibilities for coffee farmers struggling with low productivity. The U.S. NGO Radio Lifeline was also involved, contributing experience from its previous biochar project in Rwanda. The aim was to improve coffee yields, soil structure, and soil moisture content, and to reduce the need for expensive fertilizers. The project made use of low-cost technology in the form of a repurposed oil drum that produced biochar from locally available waste feedstocks. In the initiative, individual farmers were selected as local intermediaries, and 25 kilns were built for the first phase. Randomized trials yielded positive results for plots treated with biochar and compost. The initiative only lasted for about a year, but included the dissemination of the technology and education. This approach seems to have been successful, because the targeted farmers have, at least in part, been reported to still be producing and applying biochar to soils at the end of 2019.

The three villages targeted in this study were identified with support from the districts, MIICO, wards, and village extension officers. The top three villages included Ikuti in Rungwe, Wasa in Mbozi, and Ihombe in Mbeya Rural. The sample frame included households with farms that apply biochar inputs during crop production. The sample (172 respondents) was randomly selected using a random number table, and consisted of the heads of households, because they are the main decision-makers at the family level. It included approximately $5 \%$ of the targeted population of total households in Wasa, Ikuti, and Ihombe. A large part of the questionnaire was designed using a Likert-style response format asking the respondents about their agreement or disagreement with various statements [32]. This enabled the creation of a hypothesis for the chi-squared test for categorical data, e.g., age, sex, income, and farm size.

The questionnaires were administered on-site in November 2019, exploring both the extent to which the biochar initiative had been acknowledged, and the reasons for continued usage or termination. In addition, key informant interviews and focus group discussions were conducted. The key agricultural decision-makers in the study area were purposively selected for the former, and heads of households were randomly selected for the latter. Quantitative data were analyzed using SPSS software version 20 and Excel spreadsheets for descriptive and inferential statistics. Qualitative data were analyzed using content analysis, in which the components of the verbal discussions were broken down into the smallest meaningful units of information, such as the perceptions, values, and attitudes of respondents. The study findings are presented in tables and figures. An overwhelming majority of the respondents were smallholder farmers with primary-level education, which is considered a low level of education in Tanzania. Of the 172 respondents, 68 (40\%) had prior knowledge of biochar, of whom 44 (26\% of the total sample) continued to use it, whereas $24(14 \%)$ had stopped doing so. Among the issues explored were motivational 
factors, such as contributions to climate mitigation, increased resilience, and a reduced need for industrial fertilizers, as well as constraints, such as technical complications.

\section{Results}

\subsection{Motives for Farmers to Engage in Biochar Use}

This study confirms that the identified and demonstrated benefits of biochar motivated smallholder farmers to engage in biochar application. Figure 1 demonstrates the motives for smallholder farmers, who are informed about biochar, to engage in biochar technology.

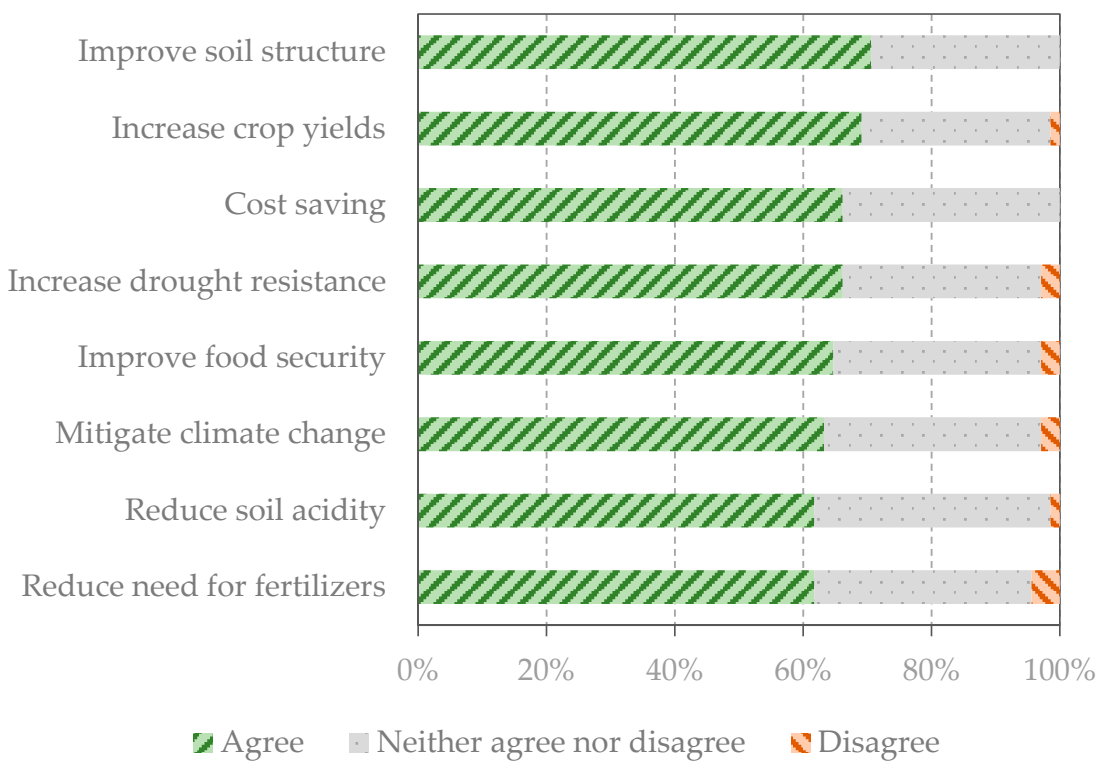

Figure 1. Motives for smallholder farmers, who are informed about biochar $(n=68)$, to engage in biochar technology.

The study shows that around $70 \%$ of the respondents with prior knowledge of biochar ( $26 \%$ of all respondents) agreed that increasing crop yields for food security and household income drove them to engage in biochar technology, listed among the key motives for using biochar, as indicated in Figure 1. Before the adoption of biochar technology, many households had been experiencing poor harvests that threatened both food security and income generation because there was little surplus to sell. The study further revealed that the reduced harvests threatened the food security, nutrition, and finances of these households, with the consequence that the proportion of households being vulnerable to poverty increased. The focus group discussion revealed that the local availability of biochar motivated smallholder farmers to engage with this technology. Biochar production was carried out mainly after harvest to ensure feedstock quality and availability. In the study area, biochar had become trusted among smallholder farmers as a cheap and efficient way of improving crop yields. The key informant interview revealed that the introduction of biochar was perceived as a solution to regain soil fertility and increase crop production in order to improve resilience and the adaptation capacity in the study area. The study and the self-assessment of smallholder farmers in the study area showed that biochar application increased crop yields; for example, coffee and maize yields increased from 1 metric ton per hectare to 3 metric tons per hectare per year. The increase in crop yields raised hopes for future food and income sustainability in Mbeya and Songwe.

The study shows that $66 \%$ of the respondents with a knowledge of biochar $(27 \%$ of respondents) agreed that a motive for using biochar technology was to increase drought resistance in the soil. It was revealed that a decrease in moisture in the soil affected crop growth and yields when exposed to extreme weather events (drought). For example, in the year 2012, coffee plants lost most of their leaves and some died during the prolonged 
dry spells in the study area in the region. The soil became dry, hindering plant growth, which resulted in pre- and post-harvest losses as farmers could not recover their financial credit from lending institutions. To overcome this situation, smallholder farmers irrigated their farms, which was expensive and environmentally unfriendly because they used diesel engines to pump water into irrigation canals. Therefore, improving the drought resistance of their farms was an anticipated outcome of biochar application to the soil, motivating farmers to invest in kilns. The key informant interview shows that biochar application did indeed have the perceived effect of contributing to moisture retention in the soil during dry seasons. It was confirmed that biochar helped perennial crops such as coffee to grow well without irrigation in Ikuti, Wasa, and Ihombe. Biochar was positively perceived as a solution to mitigate the negative effects of prolonged dry spells, which motivated smallholder farmers to apply biochar. The focus group discussion revealed that biochar adoption relieved the burden of pumping irrigation water because it increased drought resistance in coffee farms. The improved health of coffee plants during dry seasons contributed to good yields.

Another motive for farmers to engage in biochar technology was to reduce the amount of fertilizer input. The study shows that $62 \%$ of the respondents with knowledge of biochar ( $26 \%$ of all surveyed smallholder farmers) were motivated to apply biochar on their farms instead of chemical fertilizers. It was revealed during self-assessment that the application of chemical fertilizers was affordable for households with a high income, but less so for lowerincome households. Farmers spent not less than USD 200 per hectare of coffee plantations to buy chemical fertilizers. Households with low purchasing power simply could not afford to purchase fertilizers, leaving the farm without any externally sourced nutrient inputs. Decreased fertility of the soils, and failure to apply fertilizers, resulted in low yields. The perception that adding biochar to soils reduced the agricultural inputs needed by over $70 \%$ was a great motivational factor for low-income farmers to produce and use biochar. Moreover, farmers with low purchasing power who applied biochar received increased yields compared with control groups. During the focus group discussion, respondents estimated that the input of fertilizers was reduced by about half, which saved money because the previously required fertilizers were replaced by biochar.

The study shows that $71 \%$ of the respondents with knowledge of biochar $(26 \%$ of all surveyed smallholder farmers) engaged in biochar production and application to improve the structure of soils with diminishing yield capacity. The application of industrial fertilizers was perceived to have exhausted the soils, with production losses worsened by the negative impacts of climate change. It was revealed that the soil became compacted and dry, especially during the dry season, which reduced crop production. Therefore, biochar was applied to improve the structure of the soil. The results of this study revealed that biochar increased the decomposition of organic matter and thus improved soil porosity, as well as increasing the numbers of soil-living organisms, with a positive influence on yields. The key informants reported that the highly stable organic carbon in biochar may play a critical role in improving soil aggregation and stability. Changes in soil structure due to biochar application may enhance soil moisture retention and infiltration, consequently reducing runoff and erosion. Moreover, biochar application improved the soil's biological properties due to the fact that the morphology and heterogeneity of pore size distribution in biochar provides a habitat for soil organisms and protects them from predation and desiccation. Through the survey study, it was further revealed that color and soil texture enabled smallholder farmers to notice the difference, visually and through feeling the difference in the structure of soils with and without biochar. This may explain why the farmers understand this factor as by far the most important motive for producing and applying biochar. This finding may offer an entry point for educational efforts targeting awareness-raising in initiatives that seek to promote the adoption of biochar.

The study shows that another motive for smallholder farmers to engage in biochar technology is to reduce soil acidity. It was reported that $62 \%$ of the surveyed smallholder farmers, with prior knowledge of biochar (corresponding to $26 \%$ of all respondents), 
participated in biochar technology due to its ability to reduce soil acidity. The key informant confirmed that the soil in the study area was verified as acidic and unable to effectively grow coffee, which was the main cash crop in the area. It was further revealed that biochar's property of having a typically neutral to basic and relatively constant $\mathrm{pH}$, thereby neutralizing highly acidic tropical soils, was important. Therefore, smallholder farmers were motivated to apply biochar to reduce the acidity of the soil. In conjunction with collecting survey results in this study, a parallel study investigated soil properties, including soil $\mathrm{pH}$. The results indicated that soil acidity decreased when biochar was added, from an extreme $\mathrm{pH} 4.09$ to $\mathrm{pH}$ 5.68. It is very likely that reducing soil acidity has helped to improve crop health in the study area.

Mitigating the impacts of climate change by regulating the impacts of variable weather was another motive that $63 \%$ of the respondents with knowledge of biochar $(26 \%$ of all surveyed smallholder farmers) agreed had boosted their engagement with biochar production and application, as indicated in Figure 1. Smallholder farmers revealed that they had been experiencing more frequent extremely hot days in recent years, as well as greater temperature variability, than historically. Additionally, a perceived experience of decreased rainfall and changes in the length of the rainy seasons, changes associated with climate change, were seen to have led to decreases in crop production. A key informant in Wasa testified that there have been prolonged dry spells in the study area, during which ponds, tributaries, and pasture became completely dry. This affects perennial crops such as coffee as well as domesticated animals. It was further revealed that the impacts of climate change had contributed to a reduction in crop yields and pastures, which had led to pronounced poverty in the Southern Highlands of Tanzania. Therefore, during this study, smallholder farmers knew that their involvement in biochar technology was a measure intended to mitigate and adapt to climate change. Moreover, the key informants argued that biochar application can sequester atmospheric carbon and store it in soils, which will also mitigate climate change. The carbon in biochar is stable because it is a carbon concentrate of the original biomass. Its application provides climate mitigation opportunities through carbon removal, as well as potential reductions in emissions from renewable energy applications (when using waste feedstocks), and reduced methane emissions from waste decomposition. During the focus group discussions, respondents linked increasingly variable weather changes in recent years and pronounced dry spells to climate change. For example, changes in weather and a decrease in crop production resulted from the soil losing its fertility due to climate change and anthropogenic reasons.

\subsection{Socio-Economic Factors Influencing the Deployment of Biochar}

The study further revealed a detailed report on other socio-economic factors that influence biochar production and application. The socio-economic assessment was conducted among smallholder farmers to further assess perceived drivers and barriers to biochar technology. Four dimensions were explored, which were understood in previous research to influence engagement with biochar: age, education, gender, and household income. The results are shown in Figure 2, panels a-d, below and their levels of significance are shown in the appendices. The results below show that many of these socio-economic factors have indeed influenced the willingness of Tanzanian smallholder farmers to engage with biochar, and should be a primary concern for decision-making on biochar production and application.

\subsubsection{Effects of Age on Perceptions and Deployment of Biochar}

The study shows that farmers aged 40-60 years are more highly engaged in biochar production and application compared with other age groups, as shown in Figure 2a. A chi-squared test confirmed a significant difference in biochar engagement between different age categories $(p=0.001)$, as shown in Appendix A Farmers in the 40-60 age group believed that their comparatively long agriculture experience, stretching from years with relatively higher yields to recent years with an experienced decrease in the annual harvest, was a 
factor. This experience helped this age group to understand the potential significance of biochar in retaining soil fertility and mitigating the negative impacts of climate change. It was further found that farmers in this age group (40-60) were also owners of key resources such as land for cultivation, labor, and finances, which can be used for biochar production and application, which is different compared with younger age groups. It was also revealed that farmers aged 40-60 years have greater family responsibilities that require the availability of income to sustain their families' needs compared with younger or older farmers. Therefore, biochar technology may have been more easily adopted by this age group than the other age groups, as indicated in Figure 2a.

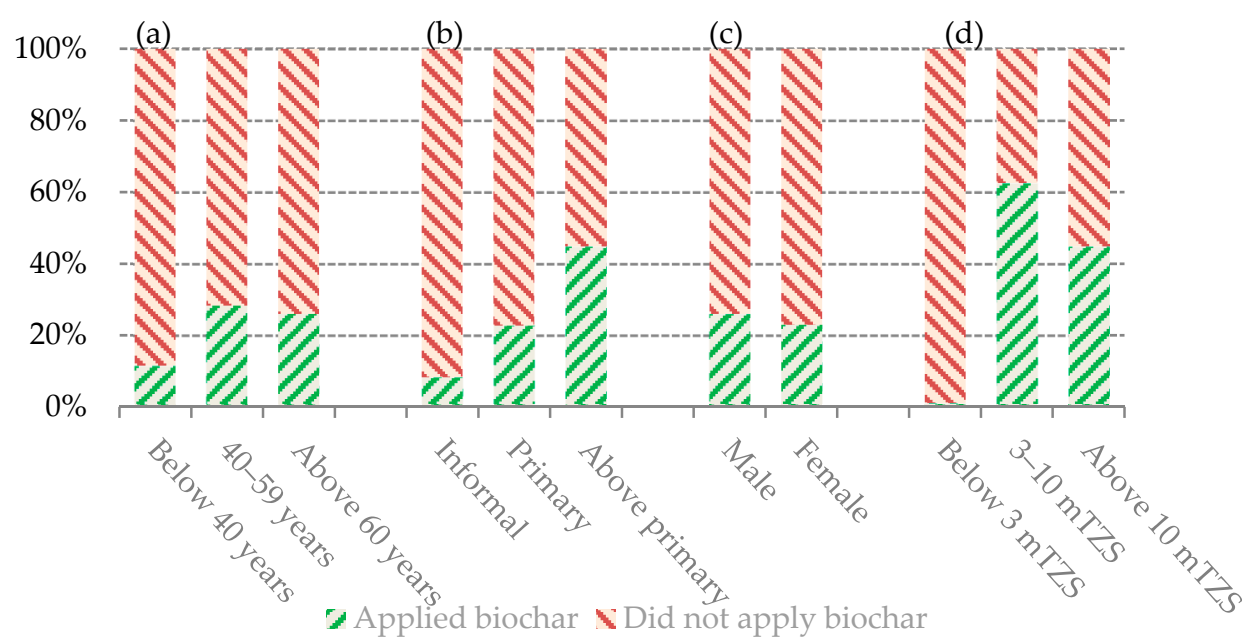

Figure 2. Distribution of level of inclination to produce and apply biochar by: (a) respondents belonging to different age categories $\left(n_{<40}=26 ; n_{40-60}=123 ; n_{>60}=23\right)$, (b) different level of education $\left(n_{\text {informal }}=12 ; n_{\text {primary }}=131 ; n_{\text {high }}=29\right),(\mathbf{c})$ gender $\left(n_{\text {male }}=146 ; n_{\text {female }}=26\right)$, and $(\mathbf{d})$ income category $\left(n_{<3 \mathrm{~m}}=95 ; n_{3-10 \mathrm{~m}}=48 ; n_{>10 \mathrm{~m}}=29\right)$.

This study further found that only $13 \%$ of farmers aged under 40 years applied biochar technology on their farms. This age group is composed of more educated people and technology champions compared with other age groups, as indicated in Figure 2a. This group might be expected to be the main agent of biochar adoption in the study area; however, there was a view that young people generally perceive agriculture as nonprofitable and laborious. Therefore, the young people in the study area reported that they had decided to engage in alternative income-generation activities, such as motor tax and small businesses in the village centers. The key informants revealed that young farmers are innovative, typically less risk-averse, and more willing to try new technologies. However, climate change and a lack of capital and reliable markets, especially in sub-Saharan Africa, reduce profits for farmers and discourage youth participation in agriculture. This implies that the future of biochar may be threatened if young and old farmers are not involved in the design and operation of biochar systems. Moreover, the study found that attempting to recruit elders' participation in biochar production and application is futile. It was found that $23 \%$ of the surveyed farmers aged over 60 years were applying biochar on their farms, as indicated in Figure 2a. Elders were perceived to have agricultural experience and available resources, especially land. This is because, before the population increase that began in 1961, the now elderly villagers acquired large pieces of land. However, elders were found to be facing deteriorating health and income, which may have hindered their participation in biochar deployment. Farmers' health largely correlates with their ability to engage in labor, and because biochar production is perceived as rather laborious, including the collection of feedstocks and organizing kilns before pyrolysis, health problems may indeed impede them from engaging with biochar. 


\subsubsection{Level of Education}

The study shows that a higher level of education (years spent in school) among smallholder farmers has been perceived as having a positive influence on their decision to adopt biochar technology. It shows that $76 \%$ of respondents had completed primary school (see Figure $2 \mathrm{~b}$ ), of whom 17\% engaged in biochar production and application. In addition, it was found that primary education barely even enabled smallholder farmers to write and count. This level of public education did not support their adoption of biochar technology. As a result, their ability to understand the biophysical and chemical characteristics of biochar was limited, resulting in a need for extension officers with biochar knowledge to explain and promote the uptake of biochar systems.

The focus group discussion revealed that poverty in their households hindered children from attending school to achieve higher education levels; instead, they were forced to work in the fields to help sustain their families. This resulted in many village members acquiring only informal and primary education, which proved challenging in acquiring biochar technology. It was further revealed that the primary and secondary schools built by the commission of the government in 2012 suffer widely from staff shortages, failing infrastructure, and a lack of teaching materials, which affect students' understanding. This may be a result of the lack of budget allocated by the government to employ more teachers, build roads, and connect the areas to the regional or national electricity grid, which would motivate teachers and students to study and test their ideas in laboratories.

A chi-squared test confirmed a statistically significant influence of education level on biochar production and use $(p=0.018)$, as shown in Appendix B. The key informants revealed that more years of formal education can increase farmers' ability to obtain, process, and use information relevant to the adoption of new technology. It was further revealed that low levels of education in the study area hindered agricultural development, which contributed to maintaining old agricultural practices with minimal production levels in the district. On the other hand, lack of formal education among farmers who were attracted to local beliefs and traditional farming led to lower yields and prolonged soil exhaustion. For example, applying black residue "char" to the soil was termed witchcraft. This further indicates that low education levels in the study area may have affected farmers' decisions about adopting biochar systems. Therefore, this finding indicates that a high level of education can lead to a positive correlation in understanding the science of biochar in the soils and its economic benefits.

\subsubsection{Effects of Gender on Perceptions and Deployment of Biochar}

In the survey sample, $85 \%$ of respondents were men. Of all the surveyed men, $26 \%$ engaged in biochar technology (see Figure 2c). Male farmers in Tanzania are generally privileged compared with female farmers in terms of access to resources and opportunities to mobilize them, including land. These male privileges are largely granted by the patriarchal system, which is widely maintained by customary laws. The study reveals that women were not allowed to decide on matters concerning land in the absence of their husbands, despite often acting as labor in agricultural activities. Moreover, widows and single mothers were required to ask for advice from their male relatives before deciding on agricultural matters, largely as a result of a strong patriarchal system that disempowers women. Key informants revealed that, in African societies with a well-established patriarchal system, men tend to have better access to resources and have inherent status as family leaders more often than women. This contrast provides men with more opportunities and a greater ability to participate in decision-making compared with women.

Therefore, men's involvement with biochar technology continues to overshadow women's. This may have caused bias in our samples and results. To avoid this, random sampling was applied (refer to Section 2). A chi-squared test showed there is a significant difference between biochar engagement among the surveyed male and female farmers $(p=0.008)$, as shown in Appendix C. This means that male farmers have a higher chance of engaging in biochar technology compared with female farmers in the study area. This 
finding contributes to explaining how biochar engagement seems to be determined by gender. Regulating the patriarchal system could allow women to participate more equally in biochar technology.

The key informant interviews revealed that agriculture, being the major source of income in the surveyed villages (as well as in Tanzania in general), contributed to men deciding to invest in biochar technology. It was further revealed that men applied biochar mostly to perennial crops, such as coffee and bananas. In their self-assessment of the effects of biochar, they reported that applying biochar to perennial crops helped them to earn more financial income to sustain their families and gain local influence. More income generation increased their social status in the community and increased their local political influence. Women instead applied biochar to annual crops such as maize and beans, in order to feed their families and send their children to school. It should be noted, however, that of the $15 \%$ female respondents, 23\% used biochar, as indicated in Figure 2c. This shows that female participation in biochar production systems is very low compared with that of men, expressed in absolute terms, but that there is also an interest in biochar among female farmers. The focus group discussion revealed that female farmers who led families were either widows or single mothers who depended on decisions made by their male relatives in all matters related to land use. It was noted that lack of land ownership due to customary laws minimized women's ability to influence decision-making or acquire technology. These reasons may have reduced female engagement in biochar production and application.

\subsubsection{Household Income and Biochar Deployment}

The majority of the surveyed smallholder farmers have low incomes, with $79 \%$ of smallholder farmers earning an annual income of about TZS 5 million, equivalent to about USD 2100. This may be a result of low agricultural production and a lack of other alternatives for income earning in the study area. In fact, respondents that earn below TZS 3 million annually almost never engage in biochar (1\%), whereas respondents that earn more than TZS 3 million do so to a high extent (56\%), As indicated in Figure $2 \mathrm{~d}$. This indicates that low income among farmers may have an impact on investment in biochar systems.

The key informant interview revealed that smallholder farmers are denied access to credit because their ability to repay their debts is low due to their low incomes. Moreover, their collateral, i.e., land, does not have title deeds. The lending scheme was designed as a strategy to improve farmers' access to finance to enable investment in biochar production, in the hope that such investment would increase their income from agriculture and reduce their vulnerability to variable weather. A chi-squared test confirmed that there is a statistically significant difference in biochar production and use depending on household income level $(p=0.025)$, as shown in Appendix D. This indicates that a higher household income helps to enable smallholder farmers who wish to invest in biochar technology.

\subsection{Constraints Preventing Farmers from Engaging in Biochar}

Despite the motives of smallholder farmers to participate in biochar technology, this study has reported on many socio-economic factors that may both drive and impede engagement in biochar systems, as shown in Figure 3.

This study shows that $82 \%$ of smallholder farmers with prior knowledge of biochar $(n=68)$ pointed out that the alternative use of biochar feedstocks was a reason for not engaging in biochar technology (see Figure 3). The study further shows that $70 \%$ and $12 \%$ of these revealed that feedstocks are used as a source of energy, e.g., for cooking, and as animal feed, respectively. The feedstocks mentioned were maize cobs (94\%), forest waste $(4 \%)$, and animal manure ( $2 \%)$. The key informants reported that some biomass types that are suitable for biochar production are instead used as bioenergy, resulting in competition for resources between biomass energy systems and biochar production. The focus group discussion revealed that the study area was not fully connected to the national electricity grid; therefore, competition between using the biomass as a fuel and using it as a biochar 
feedstock was fierce. However, there were hopes that the national grid would soon be connected to more regions of rural Tanzania. This will reduce the potential competition between biochar production and alternative uses.

Insufficient access to experts and knowledge

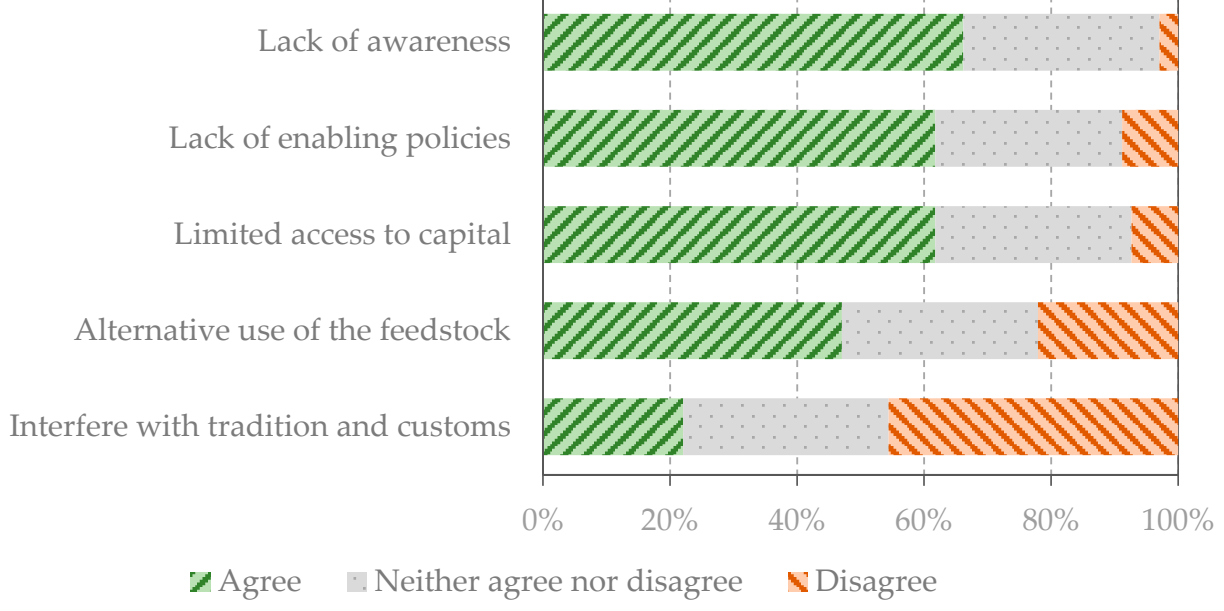

Figure 3. Constraints preventing farmers from engaging in biochar deployment (within the subsample of farmers with prior knowledge of biochar, $n=68$ ).

Of the surveyed smallholder farmers with prior knowledge of biochar $(n=68), 67 \%$ explicitly agreed that limited access to capital is a barrier to engaging with biochar technology (see Figure 3). The study further revealed a demand to purchase kilns among smallholder farmers because $66 \%$ of them had access to only one kiln, which was owned collectively by the village. In addition, $16 \%$ of smallholder farmers with knowledge of biochar accessed feedstock from other farms and paid for labor. However, the low income among smallholder farmers was insufficient to cover the costs of the technology in the study area. This finding is further supported by farmers' perception that biochar is expensive, a view held especially by the respondents who were actively engaged with biochar. Thus, costs are a likely barrier to farmers' involvement in biochar.

The key informant interview revealed that smallholder farmers could not afford the drum-based kilns that are in common use in the surveyed villages, which cost about USD 70. Although decentralized, low-cost pyrolizers such as drum kilns, which can be produced locally, appear to be ideal for smallholder households in sub-Saharan Africa, the cost of these drum-kilns was still seen as unaffordable by many farmers in the Southern Highlands of Tanzania. The focus group discussion revealed that a lack of low-cost, longterm financing options is the key barrier to biochar technology adoption in Tanzania. This fact motivated the donation of kilns from the organizations promoting biochar, such as the Black Earth Project in 2014. It was further revealed that 25 kilns were donated to villages which agreed to participate in a biochar training program within the Black Earth Project.

Of the survey respondents, $62 \%$ agreed that a lack of awareness about biochar challenged their engagement with biochar technology (see Figure 3). The study further revealed that lack of knowledge of pyrolysis among $63 \%$ and the potential effects of biochar on yields from the amended soil among $71 \%$ of smallholder farmers constrained their participation in biochar production and application. The key informants revealed that neither farmers nor the authorities were aware of the potential benefits of applying biochar to soils. In Tanzania, biochar is largely unknown among the population, apart from the limited group of smallholder farmers in the areas that took part in biochar initiatives in Mbeya, Dodoma, Songwe, Iringa, Morogoro, and Kagera. It was further revealed that biochar awareness in the study area was created mostly during the Black Earth Project. This involved training in pyrolysis to ensure good-quality biochar, followed by further training in its application, as 
well as the amount required per plant or hectare. Moreover, understanding the benefits of biochar to humans and the environment was emphasized in order to ensure that smallholder farmers are motivated to engage in biochar technology. However, due to budget shortfalls, the training did not last very long, nor did it cover neighboring villages. This indicates the importance of education and awareness-raising around biochar, but also the need to transfer operational skills to end-users.

Of the surveyed farmers in the Southern Highlands of Tanzania, $69 \%$ agreed that insufficient biochar experts and field experiments have constrained farmers' investment in biochar systems (see Figure 3). This result does not support the often cited expectation that local know-how about how to produce charcoal would be enough because biochar production is similar to the widespread practice of producing charcoal as a source of energy. The key informant interviews revealed that there were insufficient local biochar experts in the study area, which relates not only to production, but also to the sourcing of suitable feedstocks. This may be a result of the technology being in its infant stages, where promoting biochar expertise is needed. This indicates that there is a need for full involvement by village extension officers. Their involvement could create more experts locally. It is quite common for biochar initiatives to deploy experts during projects; however, these experts leave after the project's time has elapsed. It was noted that the long-term success of biochar initiatives depends on adequate technical support, local ownership of production systems, and the presence of experts.

The study shows that $61 \%$ of respondents cited a lack of laws, policy, and plans for biochar technology as impeding uptake (see Figure 3). The study further revealed that biochar production and application in the study area were not guided by a specific policy. There were no guidelines provided by the government concerning biochar, only experiences from other countries, such as Rwanda, where biochar has previously been utilized. The key informants argued that the introduction and adoption of new technologies are largely dependent on supportive policy and legal frameworks. For example, the Tanzania National Agricultural Policy does not provide for biochar adoption. Instead, the emphasis is on the usage of manure and compost, the application of which emits greenhouse gases such as methane and nitrous oxide. The key informants revealed that the failure to incorporate biochar into policies indicates an absence of political will which may demotivate interested parties from establishing pyrolysis plants in the country. Most governments in sub-Saharan Africa may indeed be unaware of biochar, and consequently lack a clear policy or legal framework for biochar technologies. Governments in sub-Saharan Africa have tended to support capital-intensive industrial development and associated technologies, while forgetting about biochar technology.

\section{Discussion}

This follow-up study shows that familiarity with biochar technology heightened motives for applying it on individual farms. For example, $40 \%$ of smallholder farmers claimed to be familiar with biochar, of whom $26 \%$ engaged in biochar production and application (see Section 3). The smallholder farmers cited various motives for applying biochar. These focused on achieving food security, environmental conservation, and climate change adaptation. Similar results were also reported by the authors of $[6,11]$, which are confirmed in this study with greater empirical underpinning. The total adoption of biochar technology may result in larger harvests. This is consistent with the finding of $[18,19]$, highlighting that biochar contributes to a substantial increase in coffee yields and improved water-holding capacity of soils, meaning that water is also available to plants during dry periods in the Mbeya and Songwe regions. This is consistent with previous findings [33] that biochar application reduced irrigation and fertilizer input needs by $50 \%$, and increased crop production by $70 \%$ in Rwanda. This is consistent with the author of [1], who argued that biochar has been shown to improve soil and crop productivity through enhanced nutrient and soil moisture availability. Biochar has the potential to reduce the reliance on fertilizer and its associated environmental consequences. This has emerged as being 
of great interest in countries such as Australia, which rely on a costly foreign fertilizer supply. Biochar application has also improved seed germination and crop establishment in poor soils in Zimbabwe [3]. In Zambia, maize yield increased by between $80 \%$ and more than $400 \%$ on biochar-enriched soil relative to the control [34]. On degraded tropical soil in Kenya, biochar increased crop production by about 2.9 metric tons per hectare compared with control plots [35]. Moreover, the author of [21] demonstrated that coffee yields significantly increased in countries such as Tanzania, Ghana, Rwanda, Indonesia, Ethiopia, and Brazil.

Another motive was to reduce soil acidity (see Section 3). This finding is consistent with a study by [36]; the application of neutral and alkaline biochar has the potential to neutralize the acidity of soils, improve nutrient availability, and ameliorate microbial growth. Improving soil structure was another motive (see Section 3). This is in line with the author of [11], who argued that biochar improves the biological properties of soil, due to the morphology and heterogeneity of pore-size distribution in biochar providing a habitat for soil organisms. Biochar protects organisms from predation and desiccation. The final motive for engaging in biochar technology was mitigating the impacts of climate change (see Section 3). This is in line with the author of [11], who argued that biochar improves the biological properties of soil, due to the morphology and heterogeneity of pore-size distribution in biochar providing a habitat for soil organisms. Biochar application reduces emissions of non- $\mathrm{CO}_{2}$ greenhouse gases, e.g., reducing $\mathrm{CH}_{4}$ emissions on grassland and in the production of soya beans; reducing the emission of $\mathrm{N}_{2} \mathrm{O}$ by over $500 \%$ from municipal waste, and ammonia emissions by up to $64 \%$, and reducing total $\mathrm{N}$ losses by up to $52 \%$ during the composting of poultry litter $[3,20]$.

Achieving these goals depended on the rate of biochar adoption, the amount of biochar applied on the farms, and the socio-economic setting [2,19,35]. Biochar adoption in Tanzania is still in its infant stage and needs time and resources to develop [11]. Empirical evidence shows that the achievements of biochar application in different countries benefit both farmers and the environment $[18,21,34]$. Current biochar application in developing countries such as Tanzania needs more attention from all stakeholders to ensure its sustainable deployment in order to achieve the goals. The results described in Section 3 revealed that biochar deployment was most common amongst farmers who had been practicing agriculture for a long time. Middle-aged smallholder farmers, aged 40-60 years, were found to be more active in biochar deployment than other age groups (Section 3). This was seen to be a result of agricultural experience and the ability to invest in new technology [27]. These results indicate that farmers who have been involved in agriculture for a long time may be more conservative, with the aim of increasing agricultural profits, and may have set ways of running their farms. Meanwhile, people who have only recently entered agriculture (young people) may be more open to non-farming activities in order to earn profits quickly. These findings correspond with those of [13], that middle-aged farmers in Zimbabwe and Nigeria deployed biochar to improve soil conditions and increase crop yields to enhance climate change adaptation, respectively. However, efforts to increase youth participation have been in vain, despite being energetic and innovative (see Section 3). It was further identified that older people aged 60+ years face more economic problems and deteriorating health, which hinder their participation in the biochar system, despite being experienced in agriculture (see Section 3). It is vital to place more emphasis on youth engagement in biochar in order to guarantee sustainable adoption of the technology in the future.

The tendency for households to be headed by men more often than by women creates a bias in decision-making. For example, the results show that female-headed families were few and comprised widows and single parents, who sought advice from their male relatives when making decisions about land use. This tendency reduces women's ability to be active in decision-making, or in acquiring new technologies for their development [37]. In addition, decision-making power increases women's opportunities to engage in biochar adoption, because women are the custodians of their families. For example, women are 
responsible for taking care of their families in terms of preparing food and ensuring the well-being of both husbands and children [38].

Section 3 describes the relationship between years spent in formal education and engagement in biochar production and application by smallholder farmers. It reveals that most smallholder farmers $(76 \%)$ have a low level of education, which is likely to be unsuitable for becoming involved with the biochar system. The deployment of biochar needs planning, i.e., acquiring kilns and feedstocks, as well as the documentation of the amount of biochar applied to the soil [19]. The inability of smallholder farmers to organize and execute biochar deployment plans was partly a result of the short time they had spent in school. This indicates that education should be prioritized alongside sustainable biochar deployment. However, [39] noted that the adoption of new agricultural technology is not a one-step process; rather, it needs a proper channel and takes time for the adoption to be completed. This study highlighted the importance of household income in achieving biochar deployment (Section 3). The majority of households earned a low income, which hindered the mobilization of feedstocks and transport kilns during biochar production (Section 3). This is not the case in developed countries, where household income enables the modern design of commercial kilns for both smallholder farmers and settlers [40]. The author of [18] pointed out that farmers in Tanzania continue to operate donated drum kilns, which are collectively owned by the villages, because individual farmers cannot afford to buy their own. The author of [24] supported the finding that due to low income among farmers, which was seen to impede the ability to invest in biochar, the NCF project in Kilombero and the biochar initiative in Mtwara mobilized female farmers into groups who were introduced to a lending scheme known as the Village Community Bank (VICOBA).

This study further reveals the constraints facing biochar deployment in the study area. Section 3 revealed that securing a regular supply of sustainable and consistent feedstock is a challenge in the production of large amounts of biochar for agricultural activities because there are several competing end-users for the waste feedstocks. The same feedstocks are also used as a source of energy for cooking and fodder for animals. This finding corresponds with the findings of [41], that small Kenyan households used $25 \%$ of maize residues for feeding animals and building materials. This indicates that feedstocks may be limited by the seasonal biomass production cycle. However, the overall abundance of feedstocks in developing countries ensures sustainable biochar production.

The results given in Section 3 show that the collection and transportation of feedstocks forms a significant component of the total cost of biochar, particularly in cases where the biochar production facilities were fixed in the villages and the feedstocks have to be collected from a distant location. The cost of biochar application to soil can also be significant if specialized equipment is utilized for this operation [42]. According to the findings of [3], the real costs of developing and operating a pyrolysis plant in sub-Saharan Africa are also largely unknown. Even when such initiatives are shown to be viable on a pilot scale, accessing bank loans may be difficult and expensive due to stringent lending conditions in the region. However, the use of pyrolytic cookstoves, rather than larger kilns, is cheaper and more economically viable because the heat generated during biochar production can be used for cooking [11]. This can have considerable positive effects on the environment. Additionally, in some areas, the cost of gaining approval from regulatory agencies, local government, and the community can be significant for larger-scale pyrolysis plants, especially if waste is already being used as a feedstock.

Lack of biochar awareness has been identified as a challenge to engagement in biochar technology by smallholder farmers (Section 3). This indicates that a lack of awareness affects the application of biochar. This finding is consistent with [1], that farmers and the authorities in developing countries have no idea about biochar functions in the soil. The presence of just a few biochar initiatives and projects did not cover large areas of the country due to a lack of resources and the short time period allocated. Insufficient biochar experts may have constrained farmers from engaging in biochar production and application (Section 3). The study revealed that government extension officers were unaware of the 
benefits of producing biochar. On the other hand, it emerged that there were expectations that biochar would have enough local experts because of the notion that biochar production is more or less the same as charcoal production. However, the pyrolysis process is different from that used in charcoal making. Therefore, biochar production in the villages has been conducted by former extension officers employed by the initiatives (Black Earth Project) who reside in the villages [19]. This corresponds with the findings of [11], that most of the biochar projects in Tanzania have been dependent on external actors providing technology, expertise, and material resources.

The findings in Section 3 show that biochar production and application in the study area were not guided by any legal institution. There were no guidelines provided by the government concerning biochar, nor any other form of policy support. Only experience from other countries - such as Rwanda, where biochar application has been practiced-was used $[18,20]$. The regulatory requirements governing the application of biochar to the land are still in their infancy. The National Environmental Policy of 1997, the Environmental Management Act (EMA) of 2004, and the National Adaptation Program of Actions of 2007 in Tanzania do not mention biochar, unlike in other countries. They all introduce "Resource Recovery" to facilitate the beneficial reuse of waste for land application as organic soil fertilizers (not soil amenders), i.e., manure and compost [43-45]. The development of legal instruments will help to create a robust and transparent process, which should demonstrate that the waste confers a benefit to the soil environment, while ensuring minimal risk of harm to the environment or human health. Moreover, stating the differences between waste that poses a low risk to human health and the environment, and other waste, such as that from mixed-waste streams, which needs to be thermally treated at specialized facilities, would bring more clarity. In addition, setting conditions defining what is acceptable as a feedstock, the conditions for pyrolysis, and the characteristics of the biochar produced would be another plus.

\section{Conclusions}

In conclusion, this study confirms that socio-economic factors are key determinants for whether or not biochar will be adopted and deployed among smallholder farmers in Tanzania. Smallholder farmers use biochar to increase crop production and improve food security, aiming to generate income as well as reducing emissions to improve sustainability. Biochar technology has the potential to substantially contribute to such outcomes if it were to be adopted by a large number of smallholder farmers. The economic dimension of biochar is that it provides a cheaper option for smallholder farmers on agricultural inputs, while producing organic food which is healthy and environmentally friendly. However, the study has confirmed that biochar adoption in the study area is low; only $26 \%$ of the smallholder farmers were found to be producing and applying biochar on their farms, despite substantial external capital grants and training programs. This study concludes that age, level of education, gender, and level of income influence biochar deployment. Failure to engage young people, who are believed to be an innovative and energetic group, failure to provide formal education above primary level, and failure to empower women, whose participation is hampered by patriarchal structures and low income, has led to the slow adoption of biochar.

However, despite low adoption and deployment, the partial introduction of biochar in the Southern Highlands of Tanzania has contributed to increased agricultural productivity and adaptive capacity among smallholder farmers, and is also likely to have contributed to reductions in greenhouse gas emissions as well as atmospheric carbon removal. The more tangible effects, such as improved soil structure immediately following the application of biochar, have served as stronger motives than more complex dynamics. However, the range of motivational factors is broad and open for discussion and further studies. The results presented here concerning age, gender, education, and income call for more efforts to be allocated to overcoming these constraints. It is also clear that increasing awareness and establishing biochar initiatives, including long-term training programs, in more villages 
will increase adoption across a wider area. This could help to achieve the expected benefits of biochar technology for livelihoods and the environment.

Based on these findings, this study recommends a practical mechanism for the introduction of biochar technologies to farmers, including capacity building through training and on-farm demonstrations, organized as so-called Farmer-Field Schools. This will develop confidence and allay fears associated with the technology. Credit scheme policies that are farmer-friendly should be established to enable farmers to access the credit they need to facilitate their agricultural investments. In these schemes, young people and women should be given priority because they are groups of innovators and laborers who can contribute substantially towards biochar adoption. Giving subsidies, training, and helping to maintain good health among young people and the elderly may attract these age groups to engage in biochar production and application. Moreover, an education system that considers secondary-level education to be basic may help in the adoption of biochar technology because a primary-level education is insufficient for enabling farmers to understand the functionalities and benefits of biochar for humans and the environment.

This study extends an opportunity for further research to investigate feedstock sustainability in areas where there is intensive alternative feedstock usage in order to create baselines for each feedstock and its potential uses in the agricultural community. Furthermore, research may be needed in order to understand the lack of government participation in biochar technology, when biochar was proved to be successful years ago. More research to understand other motives that may influence biochar production and application would be beneficial, as would research to identify specific feedstocks to produce biochar that suits particular crops and soils in specific areas. In addition, suitable feedstocks for biochar should not only target biophysical parameters to maximize soil stability and positive effects on crop yields, which is a common focus in biochar research, but should also consider competition with alternative offsets as a factor that determines their suitability for use in specific locations. This study also extends the opportunity for further studies to investigate the level of acid reduction in the soil by biochar application, as well as quantifying the amount of carbon sequestered from the environment after biochar application in different areas.

Author Contributions: P.M.R., N.P. and M.F. wrote and compiled the paper, established the methodology, software, and validation, conducted the data analysis, and prepared the tables and figures. P.Y., S.H. and A.H. supervised the organization of resources and assisted with manuscript compilation, application of the method, editing, and co-authorship of the paper. All authors have read and agreed to the published version of the manuscript.

Funding: The funding for this research was provided by the Swedish Research Council [grant no. 2016-06359] and Formas [grant no. 2019-01973].

Institutional Review Board Statement: Not applicable.

Informed Consent Statement: Not applicable.

Data Availability Statement: Not applicable.

Conflicts of Interest: We declare that this manuscript is original, has not been published before, and is not currently being considered for publication elsewhere. We know of no conflict of interest associated with this publication. The data collection fund given to the University of Dar es Salaam, Tanzania, from Linköping University, Sweden, has no conflict of interest with this publication. As corresponding author, I confirm that the manuscript has been read and approved for submission by all the named authors. 


\section{Appendix A. Test for Age and Biochar Deployment}

Table A1. Shows statistical significance between age and biochar deployment.

\begin{tabular}{cccc}
\hline & Value & df & Asymp. Sig. (2-Sided) \\
\hline Pearson Chi-Square & $18.329^{\mathrm{a}}$ & 4 & 0.001 \\
\hline Likelihood Ratio & 22.343 & 4 & 0.000 \\
\hline Linear-by-Linear Association & 4.771 & 1 & 0.029 \\
\hline N of Valid Cases & 172 & & \\
a. 1 cells (10.0\%) have expected count less than 5. The minimum expected count is 3.07. &
\end{tabular}

\section{Appendix B. Test for Education and Biochar Deployment}

Table A2. A statistical significance between education and biochar deployment.

\begin{tabular}{cccc}
\hline & Value & df & Asymp. Sig. (2-Sided) \\
\hline Pearson Chi-Square & $8.012^{\mathrm{a}}$ & 2 & 0.018 \\
\hline Likelihood Ratio & 7.858 & 2 & 0.020 \\
\hline Linear-by-Linear Association & 7.775 & 1 & 0.005 \\
\hline N of Valid Cases & 172 & & \\
\hline a & &
\end{tabular}

a. 1 cells $(16.7 \%)$ have expected count less than 5. The minimum expected count is 3.07.

\section{Appendix C. Test for Gender and Biochar Deployment}

Table A3. Shows a statistical significance between gender and biochar deployment.

\begin{tabular}{|c|c|c|c|c|c|}
\hline \multicolumn{6}{|c|}{ Chi-Square Tests } \\
\hline & Value & df & Asymp. Sig. (2-Sided) & Exact Sig. (2-Sided) & Exact Sig. (1-Sided) \\
\hline Pearson Chi-Square & $5.101^{\mathrm{a}}$ & 1 & 0.0751 & & \\
\hline Continuity Correction ${ }^{\mathrm{b}}$ & 6.005 & 1 & 0.0941 & & \\
\hline Likelihood Ratio & 5.103 & 1 & 0.0748 & & \\
\hline Fisher's Exact Test & & & & 1.000 & 0.482 \\
\hline Linear-by-Linear Association & 7.100 & 1 & 0.0751 & & \\
\hline $\mathrm{N}$ of Valid Cases & 172 & & & & \\
\hline
\end{tabular}

\section{Appendix D. Test for Household Income and Biochar Deployment}

Table A4. Shows a statistical significance between household income and biochar deployment.

\begin{tabular}{|c|c|c|c|c|c|}
\hline \multicolumn{6}{|c|}{ Chi-Square Tests } \\
\hline & Value & df & Asymp. Sig. (2-Sided) & Exact Sig. (2-Sided) & Exact Sig. (1-Sided) \\
\hline Pearson Chi-Square & $5.008^{\mathrm{a}}$ & 1 & 0.025 & & \\
\hline Continuity Correction ${ }^{b}$ & 4.093 & 1 & 0.043 & & \\
\hline Likelihood Ratio & 5.717 & 1 & 0.017 & & \\
\hline Fisher's Exact Test & & & & 0.031 & 0.017 \\
\hline Linear-by-Linear Association & 4.979 & 1 & 0.026 & & \\
\hline $\mathrm{N}$ of Valid Cases & 172 & & & & \\
\hline
\end{tabular}




\section{References}

1. Scholz, S.M.; Sembres, T.; Roberts, K.; Whitman, T.; Wilson, K.; Lehmann, J. Biochar Systems for Smallholders in Developing Countries: Leveraging Current Knowledge and Exploring Future Potential for Climate-Smart Agriculture; The World Bank: Washington, DC, USA, 2014.

2. Lehmann, J.; Stephen, J. Biochar for Environmental Management Science and Technology: Natural Resources Management, Energy, Climate, Agriculture, 1st ed.; Taylor \& Francis Group: London, UK, 2009.

3. Gwenzi, W.; Chaukura, N.; Mukome, F.N.; Machado, S.; Nyamasoka, B. Biochar Production and Applications in Sub-Saharan Africa: Opportunities, Constraints, Risks and Uncertainties. Environ. Manag. 2015, 150, 250-261. [CrossRef] [PubMed]

4. $\quad$ Liang, B.; Lehmann, J.; Solomon, D.; Kinyangi, J.; Grossman, J.; O’Neill, B.; Neves, E.G. Black Carbon Increases Cation Exchange Capacity in Soils. Soil Sci. Soc. 2006, 70, 1719-1730. [CrossRef]

5. Novak, J.; Busscher, W.; Laird, D.; Ahmedna, M.; Watts, D.; Niandou, M. Impact of Biochar Amendment on Fertility of a Southeastern Coastal Plain Soil. Soil Sci. 2009, 174, 105-112. [CrossRef]

6. Lane, J. An Overview of the current Biochar and Activated Carbon Markets. Biofuels Digest, 11 October 2016.

7. Sieber, S.; Jha, S.; Shreef Tharayil, A.-B.; Bringe, F.; Crewett, W.; Uckert, G.; Klaus, M. Integrated assessment of sustainable agricultural practices to enhance climate resilience in Morogoro, Tanzania. Reg. Environ. Chang. 2015, 15, 1281-1292. [CrossRef]

8. Kiobia, D.O.; Graef, H.A.; Reuben, P.; Kahimba, F.C.; Graef, F.; Eichler-Löbermann, B.; Silayo, V.C. Combining Biochar with Low Rate of Chemical Fertiliser Boosts Maize Biomass Yield, Regardless of Tillage System, Under Humid Conditions. J. Agric. Rural. Dev. 2019, 120, 55-62.

9. Salgado, H.M.; Coba, S.J.; Tarelho, L.A. Simultaneous Production of Biochar and Thermal Energy Using Palm Oil Residual Biomass as Feedstock in an Auto-thermal Prototype Reactor. J. Clean. Prod. 2020, 266, 121804. [CrossRef]

10. Leng, L.; Xu, X.; Wei, L.; Fan, L.; Huang, H.; Li, J.; Zhou, W. Biochar Stability Assessment by Incubation and Modelling: Methods, Drawbacks and Recommendations. Sci. Total Environ. 2019, 664, 11-23. [CrossRef]

11. Hansson, A.; Haikola, S.; Fridahl, M.; Yanda, P.; Mabhuye, E.; Pauline, N. Biochar as Mult-purpose Sustainable Technology: Experiences of Projects in Tanzania. Environ. Dev. Sustain. 2020, 23, 5182-5214. [CrossRef]

12. Fridahl, M.; Haikola, S.; Rogers, P.M.; Hansson, A. Biochar Deployment Drivers and Barriers in Least Developed Countries. In Handbook of Climate Change Management; Leal Filho, W., Luetz, J.M., Ayal, D., Eds.; Springer Nature: Cham, Switzerland, 2021.

13. Ajewole, O.C. Farmer's Response to Adoption of Commercially Available Organic Fertilizers in Oyo state, Nigeria. Afr. J. Agric. Res. 2010, 5, 2497-2503.

14. Leyaro, V.; Morrissey, O. Expanding Agricultural Production in Tanzania: Scoping Study for IGC Tanzania on the National Panel Surveys; International Growth Centre: London, UK, 2013.

15. Chang'a, L.B.; Yanda, P.Z.; Ngana, J. Indigenous knowledge in seasonal rainfall prediction in Tanzania: A case of the South-western Highland of Tanzania. J. Geogr. Reg. Plan. 2010, 3, 66-72.

16. Pedram, R.; David, B.L.; Linderman, M.; Ramankutty, N. Climate Variability and Crop Production in Tanzania. Agric. For. Meteorol. 2011, 151, 449-460.

17. Warner, K.; Afifi, T. Where the Rain Falls: Evidence from 8 Countries on how Vulnerable Households Use Migration to Manage the Risk of Rainfall Variability and Food Insecurity. Clim. Dev. 2013, 6, 1-17. [CrossRef]

18. Brown, N. Daily Coffee News. Retrieved 8 May 2019. Available online: https:/ / dailycoffeenews.com/2017/07/18/low-costbiochar-application-in-tanzania-shows-astounding-increases/ (accessed on 18 July 2019).

19. Cosmidis, L.; Siwingwa, A. Biochar IVS Project Tembo-MIICO Final Project; Tembo Coffee Company: Mbeya, Tanzania, 2017; unpublished.

20. Draper, K. The Potential for Biochar to Improve Sustainability in Coffee Cultivation and Processing: A White Paper; International Biochar Initiative: New York, NY, USA, 2018.

21. IBI. 2018 International Biochar Initiative. Retrieved 26 May 2019. Available online: https://biochar-international.org/biocharfeedstocks / (accessed on 18 July 2019).

22. NFD. From Waste to Local Business Development and Vigorous Soil, Tanzania: Final Report; Nordic Climate Facility: Dar es Salaam, Tanzania, 2017.

23. Silayo, V.; Yustas, Y.; Munder, S.; Uckert, G.; Muller, J.; Elly, N.; Hoffmann, H. Pyrolysis for Energy and Biochar Production in Rural Areas. Available online: http:// project2.zalf.de/trans-sec/public/media/factsheets/Trans-SECfactsheet2.pdf (accessed on 22 May 2020).

24. NFC. Products: Charcoal/Biomass. Retrieved from the New Forests Company. Available online: http://newforests.net/products/ charcoalbiomass / (accessed on 22 May 2020).

25. Krause, A.; Rotter, V.S. Recycling Improves Soil Fertility Management in Smallholdings in Tanzania. Agriculture 2018, 8, 31. [CrossRef]

26. Fru, B.S.; Angwafo, T.E.; Martin, T.N.; Francis, N.A.; Ngome, T.P. Environmental and Socio-economic Feasibility of Biochar Application for Cassava Production in the Bimodal Rainforest Zone of Cameroon. Int. J. Rural. Dev. Environ. Health Res. 2018, 2 1-9. [CrossRef]

27. Munoz, L. Spreading the Char: The Importance of Local Compatibility in the Diffusion of Biochar Systems to the Smallholder Agriculture Community Context; Pomona College: Claremont, CA, USA, 2014. 
28. Gitau, J.K.; Mendum, R.; Njenga, M. Gender and improvement of Cooking Systems with Biochar-producing Gasifier Stoves. In IWMI, Recovering Bioenergy in Sub-Saharan Africa: Gender Dimensions, Lessons and Challenges; International Water Management Institute (IWMI): Colombo, Sri Lanka, 2018; pp. 49-56.

29. Rogers, P.M. Contribution of Biochar in Agricultural Production in Southern Highlands of Tanzania: The Case of Rungwe, Mbozi, and Mbeya Rural. Master's Thesis, The University of Dar es Salaam, Dar es Salaam, Tanzania, 2020.

30. Kibue, G.W. Use of Biochar for Increased Crop Yields and Reduced Climate Change Impacts from Agricultural Ecosystems: Chinese Farmers' Perception and Adoption Strategy. Afr. J. Agric. Res. 2018, 13, 1063-1070.

31. Uaiene, R.N.; Arndt, C.; Masters, W. Determinants of Agricultural Technology Adoption in Mozambique; Discussion Papers No. 67E; Ministry of Planning and Development: Tete, Mozambique, 2009.

32. Likert, R. A technique for the measurement of attitudes. Arch. Psychol. 1932, 22, 55.

33. Milwaukee. Anodyne Coffee Roasting Co. Stands up for African Farmers. Retrieved from OnMilwaukee. Available online: https:/ / onmilwaukee.com/articles/anodyneandradiolifeline (accessed on 13 January 2016).

34. Cornelissen, G.; Martinsen, V.; Shitumbanuma, V.; Alling, V.; Breedveld, G.D.; Rutherford, D.W.; Mulder, J. Biochar Effect on Maize Yield and Soil Characteristics in Five Conservation Farming Sites in Zambia. Agronomy 2013, 3, 256-274. [CrossRef]

35. Kimetu, J.M.; Johannes, L.; Ngoze, S.; Mugendi, D.; Kinyangi, J.; Riha, S.; Pell, A.N. Reversibility of Soil Productivity Decline with Organic Matter of Differing Quality along a Degradation Gradient. Ecosystems 2008, 11, 726-739. [CrossRef]

36. Zhang, M.; Riaz, M.; Zhang, L. Biochar Induces Changes to Basic Soil Properties and Bacterial Communities of Different Soils to Varying Degrees at 25 mm Rainfall: More Effective on Acidic Soils. Front. Microbiol. 2019, 10, 1321. [CrossRef]

37. Shekilango, S.M. Microcredit and Empowerment of Rural Women Experience from Mbeya Region Tanzania. Master's Thesis, Lund University, Lund, Sweden, 2012.

38. Liwenga, E.T. Food Insecurity and Coping Strategies in Semiarid Areas: The Case of Mvumi in Central Tanzania; Intellecta DocuSys AB: Sollentuna, Sweden, 2003.

39. Ferdi. Learning for Adopting: Technology Adoption; Fondation Pour les Études et Recherches: Clermont-Ferrand, France, 2016.

40. USBI. 2019 Biochar Production. Available online: http:/ / biochar-us.org/biochar-production (accessed on 4 June 2019).

41. Torres-Rojas, D.; Lehmann, J.; Hobbs, P.; Joseph, S.; Neufeldt, H. Biomass Availability, Energy Consumption and Biochar Production in Rural Households of Western Kenya. Biomass Bioenergy 2011, 35, 3537-3546. [CrossRef]

42. Torres, D. Biochar Production with Cook Stoves and Use as a Soil Conditioner in Western Kenya. Master's Thesis, Cornell University, Ithaca, NY, USA, 2011.

43. URT. The National Environmental Policy; The Government Printing Press: Dar es Salaam, Tanzania, 1997.

44. URT. Environmental Management Act; Gocernment Printing Press: Dar es Salaam, Tanzania, 2004.

45. NAPA. National Adaptation Programme of Action; Vice President's Office: Dar es Salaam, Tanzania, 2007. 